\title{
Agro-Ecological Zones, Breed Type And Animal Management Styles Association With The Prevalence Of The GI Parasites In Cattle Of Kirinyaga County, Kenya
}

\author{
F K Njonge ${ }^{1 *}$ \\ ${ }^{I}$ (Department of Animal Science, Jomo Kenyatta University of Agriculture and Technology, P.O Box 62000- \\ 00200, Nairobi, Kenya)
}

\begin{abstract}
The aim of the study was to determine the prevalence of helminths in cattle in Kirinyaga County in association with the agro-ecological zones, breed types and animal management styles. Epidemiological data was collected using a questionnaire survey administered to 244 respondents. Fecal samples from cattle were collected within a period of four months to determine helminths and protozoa egg counts. The study revealed that there was a significant association between the type of management style used and helminth infestation. The grazing style of management significantly related to helminths infection $(P<0.05)$. When considering the various cattle breeds, Arshyires and Friesians were significantly associated with helminth infection at 24 and 50 times higher than the crosses and zebu breeds. Helminth presence was significantly associated with agro ecological zone from which cattle came from. Coccidia was significantly associated with age and breed of cattle $(P<0.005)$. The calves were 4 times more likely to be affected by coccidia than adult cattle while the yearlings were about 3.8 times more likely to be affected by coccidia. The Friesian was 4.9 times more susceptible to coccidia infection than other breeds. In conclusion, during the control and treatment of cattle helminthiasis, agro-ecology, species, age and sex of the animals should be considered as potential risk factors for the occurrence of the disease in the study areas.
\end{abstract}

Keywords: Age, Agro ecological zones, Animal management styles, Breed types, Helminths and Sex

\section{Introduction}

The Kenyan economy is mainly dependent on agriculture as $75 \%$ of its population depends on agriculture for food and income. It contributes $26 \%$ to the Gross Domestic Product (GDP) and $60 \%$ to foreign exchange earnings. Two thirds of the Kenyan land area is semi-arid to arid, and characterized by low, unreliable and poorly distributed rainfall. These areas are used for pastoral farming [1]. Kirinyaga County has a varied tropical climate, influenced by its proximity to the equator as well as altitude in the location within the highlands of Mt. Kenya.

The main livestock activity in the Kirinyaga County is dairy production. In terms of volume and value, it contributes to more than $80 \%$ of the productions of livestock. This type of farming is mainly practiced as a small-scale activity in the high potential areas of Ndia and Gichugu divisions (uplands) mainly due to the small size of the farm holdings which average between 1-3 acres [2]. One to three (1-3) dairy cows are kept by smallholder farmers under semi-zero-grazing and zero grazing systems. The breeds kept include crossbreeds of Guernsey, Aryshires, and Friesians and some indigenous breeds. An average of 50\% of the milk produced is consumed within households in the county; the remainder is sold to dairy societies, local hotels, institutions and individuals. Beef cattle are kept in Mwea division (lowlands). Local Zebu cattle breeds are the main breed types kept. These indigenous cattle provide milk and provide draught power for ploughing, land preparation in the rice paddies and drawing goods carts.

Parasitism is of supreme importance in many agro-ecological zones and still a serious threat to the livestock economy worldwide [3]. In the tropics gastrointestinal helminth infections are a major constraint to livestock production [4]. They cause mortality [5], high economic losses as well as lowering the level of production [6,7], affecting the income of small holder dairy farming communities. To formulate and implement an effective strategic helminth control regime, a periodic surveillance of the prevalence of gastrointestinal helminthiasis within given environment and associated risk factors that influence their transmission is required. [8] reported that a prevalence of gastrointestinal helminths ranged from 0.72 to $84.1 \%$ in domestic animals. Many associated risk factors are influencing the prevalence of gastrointestinal Helminths including, sex, age, and weather condition and management practices [8]. It is, therefore, necessary that up-to-date information is consistently generated to guide farmers in the best management practices with regards to adoption of appropriate breeding and production technologies for improving output and productivity of various cattle breeds in Kenya. The overall aim of this study was to determine the associations of agro-ecological zones, breed types and animal management styles with the prevalence of helminths in cattle in Kirinyaga County. This would help in the 
packaging of appropriate information on better management practices to guide extension workers so that they can disseminate the same to the farmers for effective uptake pathways and adoption technologies. The introduction of the paper should explain the nature of the problem, previous work, purpose, and the contribution of the paper. The contents of each section may be provided to understand easily about the paper.

\subsection{Description of study area}

\section{Materials And Methods}

The study was conducted in Kirinyaga County, Central Kenya that covers approximately 1,478 $\mathrm{Km}^{2}$, which is 11.2 percent of old Central Province. It has an estimated population of 455,000 people and a population density of 309 persons per square kilometer. The County is located between latitude $0^{\circ}$ and $0^{\circ} 40^{\circ}$ south and longitude $37^{\circ}$ and $38^{\circ}$ east. The county consists of 21 locations and 80 sub locations. The sub locations comprises of a number of small holder farms totaling to 114,439 households. The original Kirinyaga County will be referred to in this study as the new counties have not been documented. The county lies between 1,480 m above sea level in the south to over $6,800 \mathrm{~m}$ above sea level at the mountain peak. Mt. Kenya, which is volcanic mountain, lies to the northern side of the county.

\subsection{Sampling procedure}

A questionnaire was developed and surveys conducted on the agro ecological zones, breed type and animal management styles of smallholder farmers in Kirinyaga County and were administered to randomly selected 244 farmers. The data was collected using stratified random sampling with three strata as the uplands, midlands and the lowlands zones and the samples from each stratum was selected using simple random sampling technique.

\subsection{Location and mapping of the farms}

The locations of the farms participating in the study were mapped using a Magellan global positioning system (GPS) instrument (Magellan MAP 410, California USA). The instrument was hand held and a sight was identified in the farm where there were no obstacles. The antenna of the device was directed upwards to enable the device to receive at least four clear satellite signals. Care was taken to ensure that the antenna was not under any objects that could interfere with satellite reception. The GPS device gave grid references, both latitude and longitude. It also indicated the altitude of every farm in meters above sea level. These details were recorded. The sample point coordinates (which are the indicators of the areas the questionnaires were administered) collected from the field using a GPS were typed into Microsoft Access (Microsoft Corporation) excel spreadsheet and converted to ESRI shape file using ArcGIS 9.3.1. The administrative boundary of Kirinyaga County was clipped out of the Kenya census data shape file of 1999. The data points shape file was overlaid on the Kirinyaga county administrative boundaries to create the map Figure 1.

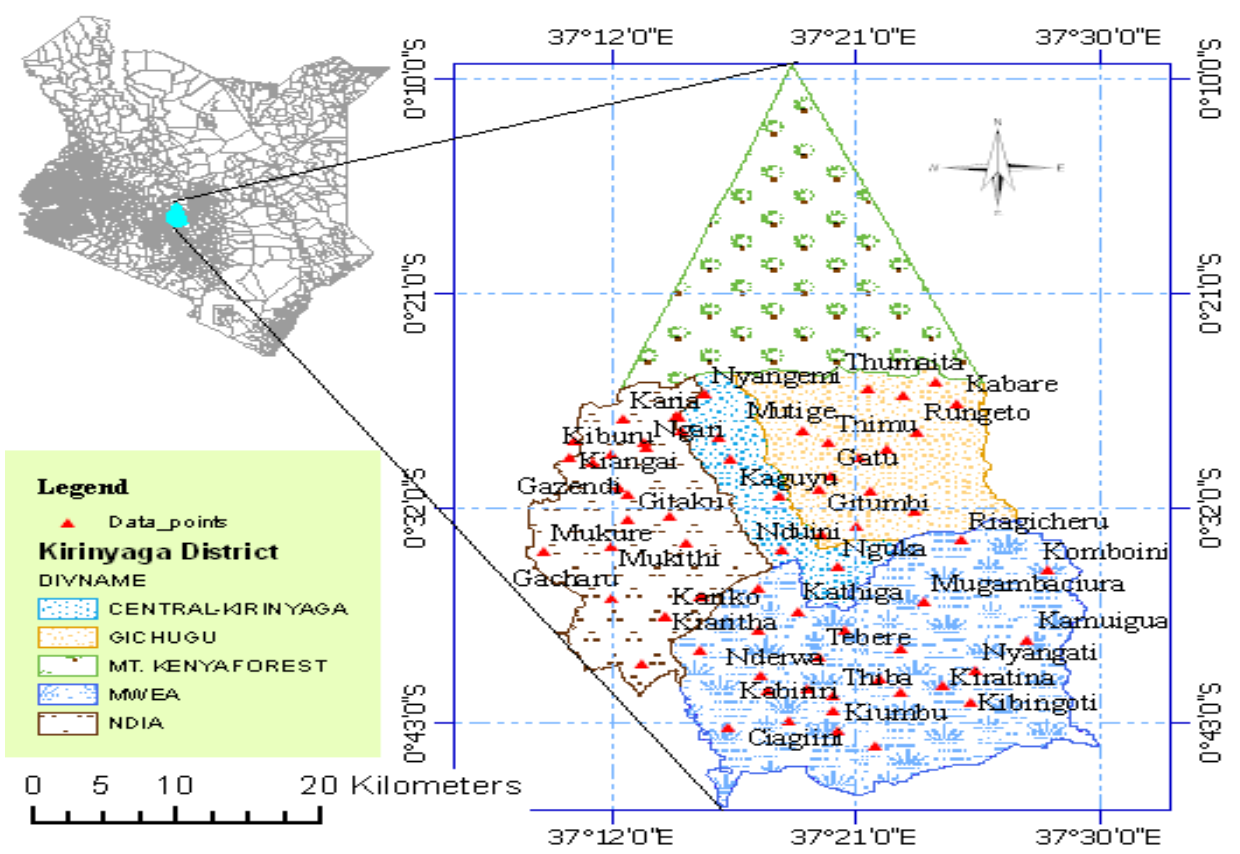

Figure 1: The map of Kirinyaga showing the sampled farms

Source: Kenya census data shape file of 1999 


\subsection{Study farms and animals}

A total of 261 cattle were sampled from the farms located in Kirinyaga County. The cattle breeds were Friesians, Aryshires, Guernsey's, crosses and Zebus. During the first farm visit the animals to be sampled were ear tagged. Other details were recorded on the individual animal record sheet which included sex, breed, age of the animal farm identification and its location, as well as the farm management practices.

\subsection{Collection and analysis of fecal samples}

Faecal samples were collected direct from the rectum from 261 cattle within a period of four months to determine helminths egg counts. The samples were labeled, placed in plastic containers and transported in a cool box to Parasitology laboratory in the Faculty of Veterinary Medicine, University of Nairobi. The faecal analysis for the presence of helminths was undertaken using McMaster method as described [9].

\subsection{Data analysis}

To model the relationship between the dependent variable (presence of helminths) and independent variables (Age, breed, agro ecological zone, Sex and Management practices) logistic regression model was used. Logistic regression, sometimes called the logistic model or logit model is used for prediction of the probability of occurrence of an event by fitting data to a logit function logistic curve. It is a generalized linear model used for binomial regression. Like many forms of regression analysis, it makes use of several predictor variables that may be either numerical or categorical. The model used was:

Logit $(\mathrm{p})=\mathrm{b}_{\mathrm{o}}+\mathrm{b}_{1} \mathrm{X}_{1}+\mathrm{b}_{2} \mathrm{X}_{2}+\mathrm{b}_{3} \mathrm{X}_{3}+\ldots+\mathrm{b}_{\mathrm{k}} \mathrm{X}_{\mathrm{k}}+\mathrm{e}$

Where:

$\mathrm{p}=$ probability of having the helminths

If a categorical variable $\mathrm{X}$ such as age is included in the model, it is first expanded into k-1 dichotomous variables where $\mathrm{k}$ is the number of categories. The dependent variable (helminth) and all the independent variables were entered into logistic regression model under forward selection procedure which automatically picked the relevant variables.

The independent variables were;

$\mathrm{X}_{1}=$ Age $(1=$ Calves, $2=$ Yearling, $3=$ Adults $)$

$\mathrm{X}_{2}=$ Breed $(1=$ Aryshire, $2=$ Friesian, $3=$ Crosses, $4=$ Zebu $)$

$\mathrm{X}_{3}=$ Agro ecological zone, $(1=$ upland, $2=$ midland, $3=$ lowland $)$

$\mathrm{X}_{4}=$ Sex, $(1=$ Male, $2=$ Female $)$

$\mathrm{X}_{5}=$ Management practices, $(1=$ Communal grazing, $2=$ Tethering,

$3=$ Semi zero grazing, $4=$ Zero grazing

$\mathrm{X}_{6}=\mathrm{PCV}$ and

$\mathrm{X}_{7}=$ Total protein.

\section{Results}

It was noted that there was a significant association between the type of management style used and helminth infestation. The grazing style of management significantly related to helminths infection $(\mathrm{P}<0.05)$. When considering the various cattle breeds, Ayrshires and Friesians were significantly associated with helminth infection at 24 and 50 times higher than the crosses and zebu breeds (Table 1). Helminth presence was significantly associated with agro ecological zone from which cattle came from, except in the midland which was not significantly different $(\mathrm{P}>0.05$.

Table 1: Association of helminths and age, type of breed and management practices fitted in logit regression model

\begin{tabular}{|l|l|l|l|l|l|l|}
\hline Dependent variable & $\mathbf{B}$ & S.E. & Wald & Df & Sig. & Exp(B) \\
\hline Breed Type & & & 16.833 & 3 & $\mathbf{0 . 0 0 1}$ & \\
\hline Breed Type(1) & 3.187 & 1.022 & 9.726 & 1 & $\mathbf{0 . 0 0 2}$ & 24.221 \\
\hline Breed Type(2) & 3.924 & 0.999 & 15.416 & 1 & $\mathbf{0 . 0 0 0}$ & 50.586 \\
\hline Breed Type(3) & 0.747 & 0.731 & 1.045 & 1 & $\mathbf{0 . 3 0 7}$ & 2.111 \\
\hline Agro Ecological & & & 13.510 & 2 & $\mathbf{0 . 0 0 1}$ & \\
\hline Agro Ecological(1) & -3.732 & 1.126 & 10.982 & 1 & $\mathbf{0 . 0 0 1}$ & 0.024 \\
\hline Agro Ecological(2) & -1.645 & 0.852 & 3.731 & 1 & $\mathbf{0 . 0 5 3}$ & 0.193 \\
\hline Animal Management & & & 20.309 & 3 & $\mathbf{0 . 0 0 0}$ & \\
\hline Animal Management(1) & -3.485 & 0.776 & 20.184 & 1 & $\mathbf{0 . 0 0 0}$ & 0.031 \\
\hline Animal Management(2) & -3.322 & 1.233 & 7.255 & 1 & $\mathbf{0 . 0 0 7}$ & 0.036 \\
\hline Animal Management(3) & -3.609 & 1.067 & 11.440 & 1 & $\mathbf{0 . 0 0 1}$ & 0.027 \\
\hline
\end{tabular}

Coccidia was significantly associated with age and breed of cattle $(\mathrm{P}<0.005)$. The calves were approximately 4 times more likely affected by coccidia than adult cattle while the yearlings were about 3.8 times more likely to be affected by coccidia. The Friesian was 4.9 times more susceptible to coccidia infection than other breeds (Table 2). 
Agro-ecological zones, breed type and animal management styles association with the prevalence....

Table 2. Association of age and type of breed with the coccidia infection in cattle in Kirinyaga county

\begin{tabular}{|c|c|c|c|c|c|c|}
\hline Dependent variable & B & S.E. & Wald & df & Sig. & $\operatorname{Exp}(\mathbf{B})$ \\
\hline Age. & & & 23.977 & 2 & 0.000 & \\
\hline Age.(1) & 1.434 & 0.379 & 14.329 & 1 & 0.000 & 4.195 \\
\hline Age. (2) & 1.351 & 0.344 & 15.415 & 1 & 0.000 & 3.862 \\
\hline BreedType & & & 14.077 & 3 & 0.003 & \\
\hline BreedType(1) & 0.826 & 0.353 & 5.476 & 1 & 0.019 & 2.284 \\
\hline BreedType(2) & 1.598 & 0.474 & 11.383 & 1 & 0.001 & 4.943 \\
\hline BreedType(3) & 0.215 & 0.422 & 0.259 & 1 & 0.611 & 1.240 \\
\hline
\end{tabular}

\section{Discussion}

According to [10], the regression model can be used to identify the factors association with the prevalence of the helminths in the study area. In this study the breed type was a significant factor and highly associated with presence of helminths in this area. The Friesian was more susceptible to helminth infestation than the other breeds and this breed was $50.6 \%$ more likely to be infected than the cross breeds and the zebu cattle. Zebu cattle which are known to be hardy animals and more resistant to helminth infestation were less likely to be associated with helminth infestation as predicted by the model. It is well documented that a number of factors will affect the outcome of infections with parasites, among them age, breed, sex, management practices and agro ecological zoning among others [11, 12]. The study demonstrated that the ecological zones where cattle are reared were a significant factor in determining the presence of helminth. This observation has also been documented elsewhere. In a study in Kisumu, Kenya, [13] demonstrated that the origin of cattle was significantly associated with presence of trematodes and Paramhistomum had a significantly higher association with the breed of cattle. In this study, it was also clear that indigenous cattle breeds were highly associated with Paramhistomum than exotic breeds. Furthermore, management practices were significantly associated with the helminth presence in any of the agro ecological zone and communal grazing was significantly highly associated with helminths. The management of cattle is an important factor farmers need to consider because it has a direct effect on the productivity and reproduction aspects of cattle performance. Two types of cattle management, traditional and modern were identified as associated with cattle helminths in a study to assess the impact of different management on incidence of helminths in various cattle age groups. These findings of the current study agree. Host age, sex, diet and season also played a significant role in determining helminths species concentration in cattle, sheep and goats [14]. For instance, host age seems to play a major role in determining species concentration and helminth diversity. When considering season, the survival of most nematodes eggs is higher under moist conditions. This is probably the reason why the upland area which experiences higher amounts of rainfall compared to the midlands and lowlands had a significant influence on the worm load in the cattle examined which agrees with the findings reported by others. An alternate view [15] attributed the higher parasite loads in the dry season to various reasons, such as transmission, diet, body condition, and uneven sampling across age classes/ sexes. However, depending on differences in parasite prevalence, differences between the age, classes, sex and patterns of nematode presence may suggest that parasitic infections may be affected by other factors modulated by host-intrinsic factors. The model used in the current study showed that communally grazed, semi grazed and tethered cattle in that order has increasing prevalence. Considering that most of helminths are transmitted orally by ingesting the infective stage in contaminated food and water, the observed high prevalence in grazed animals may be caused by highly contaminated grazing sites. The diet type affects the faecal egg counts of nematodes in cattle. In this regard, the source of the feed and the management practice may also be other factors associated with nematode load in this study.

The logit regression model was able to identify age of cattle and breed type as the two factors influencing coccidia presence in the study area. The calves were highly associated with the coccidia and were 4.2 times more affected than the yearlings. Similar reports in a study in Zimbabwe [16] comparing cattle in high yield and low yield reported that there was a significantly higher prevalence of infection with coccidia in calves than in adults $(\mathrm{P}<0.01)$ and agrees with the finding of this study. Coccidia are a more serious problem in calves than adults. In a study to determine the levels of infection of coccidia in cattle in South Africa, it was reported that adult cattle had low oocyte per gram (OPG) compared to calves, which were shedding significantly higher OPG of the most pathogenic species of Eimeria [17]. Calves between 3-6 months of age group were reported to be highly susceptible to coccidiosis and had a higher prevalence rate in males than in female calves [18].

\section{Conclusion}

The agro-ecological zones from which cattle came from were significantly associated with helminth prevalence. Fluke and Schistosomes were common in the lowlands where communal grazing system was the main management practice. This was also common in uplands and midlands where zero grazing and semi zero grazing and tethering were the common management practices. There was a significant association between the type of management style used and helminth infestation. The grazing style of management significantly related 
to the helminths. Cattle breeds, especially the Aryshires and Friesians they were the most affected with helminths. Further studies are required to determine the relationship between the occurrence of the parasite and environmental factors which is important in formulating a concrete deworming pattern. Moreover additional indepth helminthology studies are necessary to fully elucidate the profile of gastrointestinal parasites in order to recommend a solid helminth control program.

\section{Acknowledgements}

The author is grateful to the Director of Veterinary Services, Kenya for giving permission to carry out this research. The Chairman Department of Veterinary Pathology, Microbiology and Parasitology who allowed the use of their laboratory. Technical staff in the Parasitology laboratory University of Nairobi, especially $\mathrm{Mr}$ Richard Otieno who was useful during the data collection in the field.

\section{References}

[1] Orodho, A., B., Country Pasture/Forage Resource Profiles, KARI report, 1997.

[2] Kirinyaga, livestock disease reports, Ministry of livestock Development, 2008,2009.

[3] Vercruysse, J. and Claerebout, E, Treatment vs. non-treatment of helminth infections in cattle: defining the thresholds, Veterinary Parasitology, 98, 2001, 195-214.

[4] Githiori, J. B, Hogland, J., Waller, P. J. and Baker, R. L, Evaluation of anthelmintic properties of some plants used as livestock dewormers against Haemonchus contortus infection in sheep, Parasitology, 129, 2004, 245-53.

[5] Sykes, A.R, Parasitism and production in farm ruminants, Animal Production, 59, 1994, $155-172$.

[6] Perry, B. D. and Randolph, T. F, Improving the assessment of the economic impact of the parasitic diseases and of their control in production animals, Veterinary Parasitology, 84, 1999, 145-168.

[7] Iqbal, Z, Akhtar, M, Khan, M. N.and Riaz, M, Prevalence and economic significance of haemonchosis in sheep and goats slaughtered at Faisalabad abattoir, Pakistan Journal of Agriculture and Science, 30, 1993, 51-53.

[8] Khan, M.N, Sajid, M.S, Iqbal, Z. and Hussain, A, Gastrointestinal helminthiasis: prevalence and associated determinants in domestic ruminants of district Toba Tek Singh, Punjab, Pakistan, Parasitology Research, 107, 2010, 787-794.

[9] Hansen, J. and Perry, B, The Epidemilogy, Diagnosis and Control of Helminth Parasites of Ruminants, A handbook, International Livestock Centre for Africa, Nairobi. Kenya, 1994.

[10] Agresti, A, Categorical Data Analysis, 2nd ed. New York: John Wiley and Sons, 2002

[11] Horak, I. G. and Louw, J. P, Parasites of domestic and wild animals in South Africa: Helminths in calves on irrigated pastures on the Transvaal Highveld, Ondersterport Journal of Veterinary Research, 44,1978, 23-28.

[12] Nwosu, C.O, Madu, P.P. and Richards, W.S, Prevalence and seasonal changes in the population of gastrointestinal nematodes of small ruminants in the semi-arid zone of north-eastern Nigeria, Veterinary Parasitology, 15(144), 2007, 118-124.

[13] Kanyari, P.W. N, Kagira, J. M. and Mhoma, J. R. L, Prevalence of endoparasites in cattle within urban and peri-urban areas of Lake Victoria Basin, Kenya with special reference to zoonotic potential, Science Parasitology, 11, 2010, 171-178.

[14] Soliman, M.,F.and Zalat, S.M, Prevalence and intensity of Nematodirus sp. and Eimeria sp.infections in the domestic goats of St. Katherine's Protectorate (Sinai, Egypt): relations with some ecological and biological factors, Egypt Journal of Biology, 5, 2003, 78-85.

[15] Vidya T.N.C and Sukumar,R, The effect of some ecological factors on the intestinal parasite loads of the Asian elephant (Elephas maximus) in southern India, Journal of Bioscience, 27(5), 2002, 521-528.

[16] Pfukenyi., D, M. Mukaratirwa, S, Willingham A, L and Monrad, J, Epidemiological studies of parasitic gastrointestinal nematodes, cestodes and coccidia infections in cattle in the highveld and lowveld communal grazing areas of Zimbabwe, Onderstepoort Journal of Veterinary Research,74, 2007,129-42.

[17] Matjila, P. T. and Penzhorn B. L, Occurrence and diversity of bovine coccidia at three localities in South Africa, Veterinary Parasitology, 104, 2002, 93-102.

[18] Chigure, G.M, Narladkar B. W, KhillareB.,S, Deshpande, P.D, Digraskar ,S.U, Deshmukh, S.S, Epidemiological observations on coccidiosis in cow calves of Marathwada region, Journal of Veterinary Parasitology, 22, 2008. 